\title{
Syringe borrowing persists in Dublin despite harm reduction
}

\author{
Syringe borrowing in Dublin
}

Bobby P. Smyth, Joe Barry \& Eamon Keenan.

Addiction Research Section, AIDS/Drugs Service, Cherry Orchard Hospital, Dublin 10.

Correspondence: $\quad$ Bobby Smyth, Academic Unit, Pine Lodge, 79 Liverpool Rd., Chester CH2 1AW

Phone: $\quad$ 01244-364660

Fax: $\quad$ 01244-364659

e-mail $\quad$ bobbypsmyth@hotmail.com

Number of pages (including tables and figure) $\quad 25$

Word count ( including abstract, text \& references) $\quad 4563$

Word count ( including abstract \& text only) $\quad 3420$ 


\title{
Syringe borrowing persists in Dublin despite harm reduction
}

\author{
Bobby P. Smyth, Joe Barry \& Eamon Keenan.
}

\begin{abstract}
:
\end{abstract}
Aims: Measure the frequency of syringe borrowing in young Irish injecting drug users (IDUs) and identify associated characteristics. Design: Cross sectional survey. Setting: Addiction treatment services in Dublin. Participants: Treated IDUs $(\mathrm{N}=246)$. Measurements: Data on drug injecting and syringe borrowing in the previous six months. Findings: The median age was 22 years and the median length of injecting history was 19 months. Syringe borrowing was reported by $173(70.3 \%)$ participants. A multivariate analysis identified seven characteristics significantly associated with syringe borrowing. These included early school leaving and parental unemployment. IDUs with long injecting histories who had injected less frequently were more likely to borrow. Injection of more than one substance was significantly associated with borrowing of syringes. Syringe borrowing was associated with having more intimate social relationships with other IDUs, less perceived risk in borrowing from acquaintances and usually opting to inject in the company of other IDUs.

Conclusions: Syringe borrowing is commonly practised by young IDUs. Those with a background of social deprivation are more likely to engage in this risk behaviour. IDUs who report borrowing are more intimately involved with other IDUs and tend to perceive less risk or dangerousness in borrowing. In addition to syringe exchange, there is a need to work cognitively with IDUs to identify and challenge assumptions that they may have regarding the safety involved in borrowing from others, particularly from those with whom they have close social relationships. 


\section{Introduction:}

Improved screening of blood products has ensured that parenteral transmission of infections such as HIV and hepatitis $\mathrm{C}$ is now rare among groups such as haemophiliacs and transfusion recipients. ${ }^{1}$ By contrast efforts to reduce the incidence of these infections among injecting drug users have had more modest success, particularly in the case of hepatitis $\mathrm{C}^{2-6}$ Use of other peoples' previously used syringes (syringe borrowing) persists among IDUs despite the existence of harm reduction programs. A number of studies in the late 1990's found that about 40-45\% of IDUs reported some recent syringe borrowing. ${ }^{4,9}$ In a study conducted in Dublin in 1992, Dorman found that $57 \%$ of IDUs reported some borrowing in the previous six months. ${ }^{10}$ More recently, Cassin found that $23 \%$ of Irish IDUs attending a syringe exchange reported borrowing in the preceding month. ${ }^{11}$

Internationally, the most frequent characteristics associated with syringe borrowing include youth, ${ }^{11-14}$ shorter injecting history ${ }^{14-16}$ and being in a sexual relationship with another IDU. ${ }^{8,13,17,18}$ Those who inject stimulants, benzodiazepines or more than one substance, ${ }^{15,16,19}$ and those who inject in prison also report increased rates of borrowing. ${ }^{15,16}$ There is evidence that those who inject more frequently ${ }^{18,19}$ and those not on methadone treatment are more likely to borrow. ${ }^{13,18}$ When borrowing occurs, the donor of the syringe is most likely to be someone of close 'social proximity' such as a sexual partner or close friend. ${ }^{7,20-22}$ Loxley found that about half of IDUs believed that the risk associated with borrowing could be greatly reduced by careful selection of donor. ${ }^{22}$ Darke found that the vast majority of IDUs viewed their most recent episode of borrowing as very or fairly safe. ${ }^{17}$ Plumridge has reported that IDUs tend to retain a view of themselves as being a 'safe' and 'careful' injector, despite 
describing instances where they borrow syringes from others. ${ }^{23}$ Darke found that borrowing was not predicted by knowledge regarding HIV or perceived vulnerability to HIV. In addition to syringe borrowing, there are other important unsafe injecting practices which may contribute to spread of bloodborne viral infection. ${ }^{7}$ For example, 'halving' ( also known as 'backloading') has been shown to increase the risk of acquiring hepatitis $\mathrm{C}$ infection. ${ }^{24}$ Recently, Crofts has demonstrated the potential for substantial risk in the act of sharing injecting paraphernalia by demonstrating the presence of hepatitis $\mathrm{C}$ virus on such items as spoons and filters. ${ }^{25}$ It appears that IDUs, and possibly health professionals, may underestimate the risk posed by these activities.

\section{Setting}

Figure 1. Increase in number of syringe exchanges, outreach workers and treatment clinics in Dublin between 1991 and 1999.

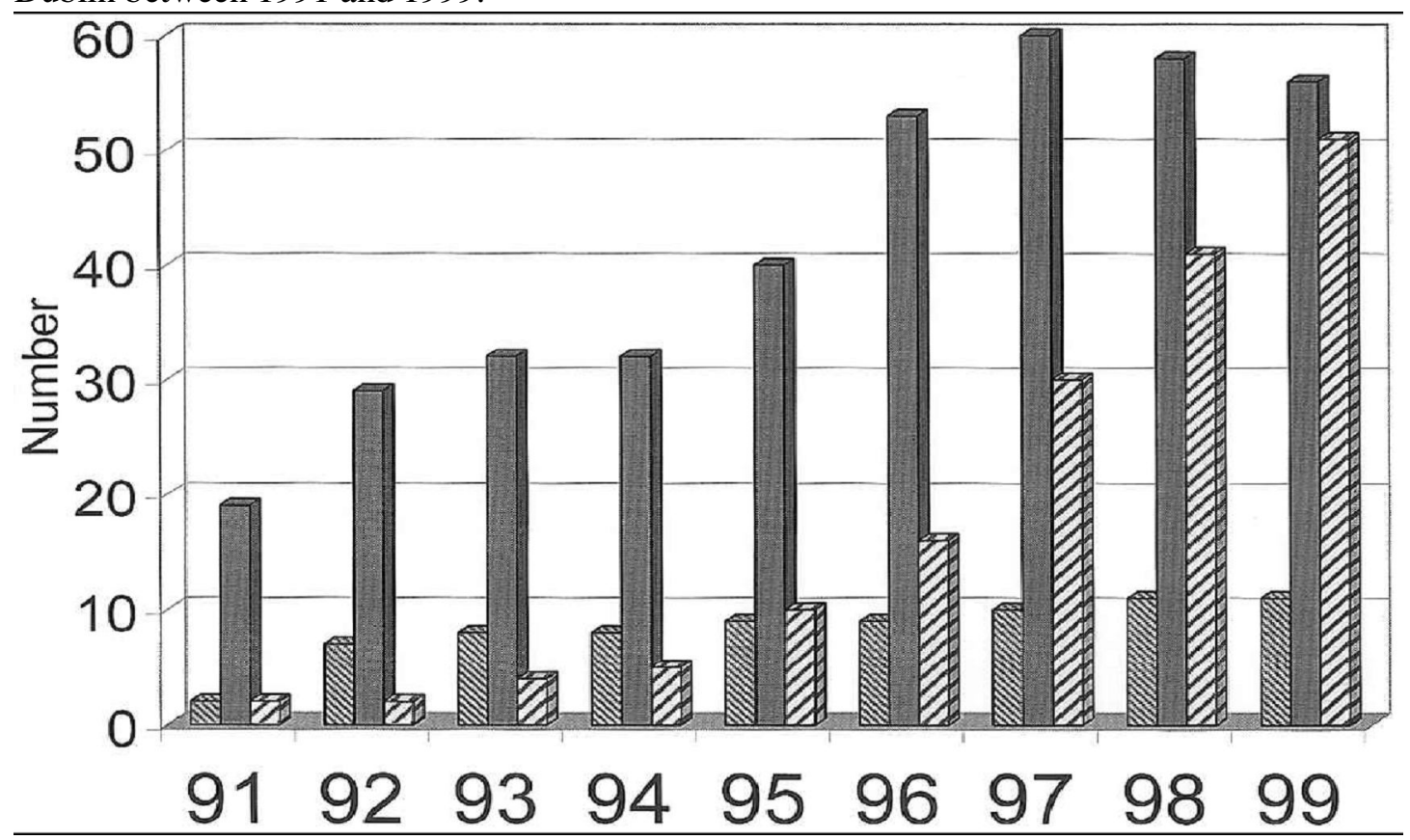

* 'Treatment clinics' includes both the large central addiction treatment centres and the more numerous small satellite clinics.

Since Dorman conducted his study in 1992, there have been no important changes to Irish legislation regarding injecting equipment. It has never been an offence to be in 
procession of a needle or syringe. However, the harm reduction program in Dublin has been reconfigured and has expanded substantially over the intervening years, as indicated in figure 1 . The restructuring was motivated by a desire to provide better outreach and a more locally delivered service, thereby improving access to syringe exchange and methadone treatment. Hence, the additional syringe exchange programs have been based in communities where drug injecting is prevalent. Access to sterile injecting equipment has been somewhat hampered by the fact that a number of these additional syringe exchanges have quite limited opening hours and there has been no twenty-four hour provision of sterile syringes such as via vending machines. Many new treatment clinics have opened and these clinics fall into one of two categories. Firstly, a small number of additional large addiction treatment centres opened and these are staffed by a fulltime multi-disciplinary team and offer a variety of therapeutic interventions, including dispensing of methadone. Secondly, a large number of smaller 'satellite' clinics have been established. The 'satellite' clinics are based in health centres or local community centres, are staffed on a part-time basis and provide prescriptions for methadone where indicated. Methadone is then dispensed in a local pharmacy. In Dublin, methadone maintenance treatment has tended to be confined to older IDUs with longer histories of opiate use. ${ }^{26}$ The mid1990s witnessed a surge in the number of heroin users presenting to addiction services in Dublin. ${ }^{27}$ Although chasing became the preferred route of use among the new heroin users, part of the increased capacity of the expanded harm reduction program will have been absorbed by this increase in patients attending for treatment. While the prevalence of hepatitis $\mathrm{C}$ infection among recent onset IDUs has dropped during the 1990s, it remains very high by international standards. ${ }^{28}$ By contrast, the prevalence of HIV among IDU in Dublin is around $1-2 \% .{ }^{29}$ Against this background, we sought to 
measure the frequency of syringe sharing in young Irish IDUs and to identify the drug misuse, social and demographic characteristics associated with syringe sharing.

\section{Method:}

Injecting drug users were recruited from a large centrally located addiction treatment centre, two specialist inpatient drug dependency units, and nine small 'satellite' clinics. A range of treatment settings were chosen to reduce the possibility of selection bias. The particular services were not randomly selected, but were chosen by the principal investigator (BPS) on the basis of the number of patients attending, their level of interest in the research project and ability to provide an appropriate interview room. We sought to include consecutive new attenders to these services who met the study entry criteria. People were eligible to participate if they had injected in the preceding six months and were of unknown hepatitis $\mathrm{C}$ status. (Those of known hepatitis $\mathrm{C}$ status were excluded due to a wider aim of this research project.) It was our aim to interview participants within the first two weeks of their attendance for treatment. Written informed consent was obtained from all participants. Interviews took place between September 1997 and June 1999. A face to face structured interview was conducted by the first author, who had no clinical involvement with the treatment service. The structured questionnaire was adapted from that used by Dorman as part of the WHO multi-centre study conducted in the early 1990 s. $^{30}$

Interviewees were assigned to one of four distinct categories to describe their 'social proximity' to other IDUs. Categories were ranked in order from closer relationships to those which were more distant. The four categories were sexual partner, close friend, 
first degree relative and acquaintance. If an individual reported knowing other IDUs from more than one group, they were assigned to the category which described their closest relationship. For example, if an individual was in a sexual relationship with another IDUs and also reported having close friends who injected and had IDUs acquaintances, they were assigned to the 'sexual partner' group. Although much previous research has examined the importance of close social relationships with other IDUs, we are unaware of any previous studies which have used the method described above to generate distinct categories of social proximity.

The perception of danger involved in borrowing a syringe from an acquaintance was measured using a 100 millimetre visual analogue scale. In order to create categories, we determined that a score of 95 millimetres or greater would equate with a perception of 'extreme dangerousness'. Knowledge regarding hepatitis $\mathrm{C}$ was assessed by asking a series of questions relating to modes of spread of this infection and scored as described elsewhere ${ }^{31}$. Following completion of the interview, participants were given the opportunity to discuss any areas of concern regarding unsafe injecting and the potential risks involved in various injecting practises were clarified.

Statistical analysis

Quantitative variables were converted into categories, usually using the median as a cut-off point. Other cut-off points were occasionally used if deemed more clinically relevant or to facilitate comparison with previous research. Pearson's chi squared test was used to examine the relationship between categorical variables and syringe borrowing. Odds ratios and their $95 \%$ confidence intervals were calculated. To control 
for possible confounding, a multivariate analysis was performed using logistic regression to identify variables independently associated with recent syringe borrowing. Variables were selected for entry into the final logistic regression equation by using both the forward stepwise and backward stepwise selection techniques. Variables selected for entry into the regression equation were examined for possible interactions.

\section{Results}

A total of 310 patients were identified as eligible to participate in the study. No interview was conducted in $66(21 \%)$ of cases. Failure to complete the interview was due to refusal in only two cases. The vast majority of those not interviewed did not happen to attend the addiction service at a time when the interviewer was on the site. Of those interviewed, 93\% were seen during their first two weeks of treatment.

Sixty per cent of participants were male. The median age was 22 years ( interquartile range [IQR] 20 to 26 years ) and the median duration of injecting was 19 months ( IQR 8 to 38 months). During the six months prior to interview the median number of injections was 360 ( IQR 90 to 630). Table 1 indicates the drugs injected by this group, their sources of sterile injecting equipment and rates of unsafe injecting during the six months prior to interview. Eighty-seven per cent had borrowed spoons or filters from other IDUs and the majority of these (82\%) did so on more then one in every ten injections. Among the 173 (70.3\%) who borrowed syringes, the median number of people from whom used syringes were borrowed was two (IQR 1 to 3 ). 
Table 1. Drugs injected, access to sterile injecting equipment and unsafe injecting practices among 246 Irish IDUs during six months prior to interview.

\begin{tabular}{|c|c|c|}
\hline & $\mathrm{N}$ & $\%$ \\
\hline \multicolumn{3}{|l|}{ Primary substance injected } \\
\hline Heroin & 239 & 97.2 \\
\hline Morphine sulphate & 4 & 1.6 \\
\hline Cocaine & 3 & 1.2 \\
\hline \multicolumn{3}{|l|}{ Secondary substances injected } \\
\hline Cocaine & 73 & 29.7 \\
\hline Morphine sulphate & 33 & 13.4 \\
\hline Amphetamine & 4 & 1.6 \\
\hline Flunitrazepam & 74 & 30.1 \\
\hline Flurazepam & 52 & 21.1 \\
\hline Diazepam & 18 & 7.7 \\
\hline Temazepam & 3 & 1.2 \\
\hline \multicolumn{3}{|l|}{ Primary source of sterile syringes ${ }^{1}$} \\
\hline NEP & 180 & 73.8 \\
\hline Other IDUs & 49 & 20.1 \\
\hline Chemist & 7 & 2.9 \\
\hline Insulin dependant diabetic (self or other) & 4 & 1.6 \\
\hline Other & 4 & 1.6 \\
\hline \multicolumn{3}{|l|}{ Secondary source of sterile syringes ${ }^{1}$} \\
\hline NEP & 11 & 4.5 \\
\hline Other IDUs & 79 & 32.4 \\
\hline Chemist & 8 & 3.3 \\
\hline Insulin dependant diabetic (self or other) & 2 & 0.8 \\
\hline Other & 4 & 1.6 \\
\hline \multicolumn{3}{|l|}{ Average number of times re-used ones own syringe ${ }^{1}$} \\
\hline Once only & 25 & 10.2 \\
\hline More than once, but less than five times & 82 & 33.6 \\
\hline More than five times & 137 & 56.1 \\
\hline \multicolumn{3}{|l|}{ Borrowing a syringe or needle } \\
\hline None & 73 & 29.7 \\
\hline Less than one in every ten injections & 117 & 47.6 \\
\hline More than one in every ten injections & 56 & 22.8 \\
\hline \multicolumn{3}{|l|}{ Backloading or 'halving', } \\
\hline None & 35 & 28.0 \\
\hline Less than one in every ten injections & 49 & 39.2 \\
\hline More than one in every ten injections & 41 & 32.8 \\
\hline \multicolumn{3}{|l|}{ Borrowing spoons/filters ${ }^{3}$} \\
\hline None & 29 & 12.6 \\
\hline Less than one in every ten injections & 37 & 16.0 \\
\hline More than one in every ten injections & 165 & 71.4 \\
\hline \multicolumn{3}{|l|}{ Passing on a used syringe/needle to another IDU ${ }^{1}$} \\
\hline No & 48 & 19.7 \\
\hline Yes & 196 & 80.3 \\
\hline
\end{tabular}


Tables 2 and 3 demonstrate the relationship between recent syringe borrowing and the recorded social and drug use characteristics. Borrowing was associated with younger age, parental unemployment, perception of less risk in borrowing from an acquaintance, being more intimately involved with other IDUs, injection of more than one substance, injection of benzodiazepines, usually injecting in company and usually injecting in locations other than a house. Recent borrowing was not associated with gender, employment, a history of imprisonment, total duration injecting, total number of injections ever, daily drug expenditure, recent injecting frequency or knowledge regarding hepatitis $\mathrm{C}$. There was no significant association between the treatment setting and syringe borrowing $(\mathrm{p}=0.19)$.

Table 2. Association between syringe borrowing and social characteristics of a multi-site sample of 246 IDUs attending treatment in Dublin

\begin{tabular}{|c|c|c|c|c|c|}
\hline & $\mathrm{N}$ & $\begin{array}{r}\text { Number } \\
\text { borrowing }\end{array}$ & $\%$ & Odds ratio $(95 \% \mathrm{CI})$ & $\mathrm{p}$ value \\
\hline Total & 246 & 173 & 70.3 & & \\
\hline \multicolumn{6}{|l|}{ Gender } \\
\hline Male & 147 & 107 & 72.8 & 1.0 & \\
\hline Female & 99 & 66 & 66.7 & $0.75(0.43-1.3)$ & 0.30 \\
\hline \multicolumn{6}{|l|}{ Age } \\
\hline Under 25 years & 177 & 135 & 76.3 & & \\
\hline 25 years and older & 69 & 38 & 55.1 & $0.38(0.21-0.69)$ & 0.001 \\
\hline \multicolumn{6}{|l|}{ Education } \\
\hline Left under 15 & 68 & 53 & 77.9 & 1.0 & \\
\hline $15 \&$ over & 178 & 120 & 67.4 & $0.59(0.30-1.13)$ & 0.11 \\
\hline \multicolumn{6}{|l|}{ Employment } \\
\hline Working & 47 & 30 & 63.8 & 1.0 & \\
\hline Unemployed & 199 & 143 & 71.9 & $1.45(0.74-2.83)$ & 0.28 \\
\hline \multicolumn{6}{|l|}{ Parental employment ${ }^{1}$} \\
\hline Working & 131 & 83 & 63.4 & 1.0 & \\
\hline Unemployed & 96 & 73 & 76.0 & $1.84(1.02-3.31)$ & 0.04 \\
\hline \multicolumn{6}{|l|}{ Imprisonment } \\
\hline Not imprisoned since started injecting & 162 & 114 & 70.4 & $0.99(0.56-1.77)$ & 0.99 \\
\hline Imprisoned after first injecting & 84 & 59 & 70.2 & 1.0 & \\
\hline \multicolumn{6}{|l|}{ Person of closest social proximity who is an IDU } \\
\hline Sexual partner & 83 & 62 & 74.7 & $2.42(1.01-5.78)$ & 0.03 \\
\hline Close friend & 106 & 75 & 70.8 & $1.98(0.87-4.48)$ & 0.07 \\
\hline $1^{\text {st }}$ degree relative & 17 & 14 & 82.4 & $3.82(0.83-19.91)$ & 0.05 \\
\hline Acquaintance & 40 & 22 & 55.0 & 1.0 & \\
\hline \multicolumn{6}{|l|}{$\begin{array}{l}\text { Perceived risk in borrowing from an } \\
\text { acquaintance }^{2}\end{array}$} \\
\hline Extremely dangerous & 124 & 78 & 62.9 & & \\
\hline Not extremely dangerous & 115 & 89 & 77.4 & $2.02(1.14-3.57)$ & 0.01 \\
\hline
\end{tabular}


Table 3. Association between syringe borrowing and drug injecting characteristics of a multi-site sample of 246 IDUs attending treatment in Dublin

\begin{tabular}{|c|c|c|c|c|c|}
\hline & $\mathrm{N}$ & $\begin{array}{r}\text { Number } \\
\text { borrowing }\end{array}$ & $\%$ & Odds ratio $(95 \% \mathrm{CI})$ & $\mathrm{p}$ value \\
\hline \multicolumn{6}{|c|}{ Past injecting characteristics } \\
\hline \multicolumn{6}{|c|}{ Time lapsed since commencing injecting } \\
\hline$<12$ months & 80 & 53 & 66.3 & 1.0 & \\
\hline $12-35$ months & 95 & 73 & 76.8 & $1.69(0.83-3.47)$ & 0.12 \\
\hline $36+$ months & 71 & 47 & 66.2 & $1.00(0.48-2.07)$ & 0.99 \\
\hline \multicolumn{6}{|c|}{ Number of injections ever } \\
\hline$<1000$ & 114 & 83 & 72.8 & 1.0 & \\
\hline $1000+$ & 132 & 90 & 68.2 & $0.80(0.46-1.39)$ & \\
\hline
\end{tabular}

Injecting profile in past six months only

Number of substances injected ${ }^{2}$

One
Two

$\begin{array}{rrrrr}92 & 50 & 54.3 & 1.0 & \\ 78 & 61 & 78.2 & 3.01(1.46-6.28) & 0.001 \\ 75 & 61 & 81.3 & 3.66(1.70-7.95) & <0.001\end{array}$

Injection of stimulants

No

169

116

68.6

Yes

Injection of benzodiazepines

No

Yes

Days injecting per month

$$
\begin{aligned}
& \text { Every day } \\
& 16-29 \text { days }
\end{aligned}
$$

1-15 days

Frequency of injecting on injecting days

$$
\begin{aligned}
& 1.0-2.0 \\
& 2.1-3.0 \\
& >3.0
\end{aligned}
$$

Daily drug expenditure ${ }^{3}$

$$
£ 1 \text { to } £ 65
$$

$£ 66+$

Usual location when injecting ${ }^{4}$

A house (own/friends)

Outside/variable

Usual company when injecting $^{5}$

On Own $\quad 50$

With one other IDU

With more than one other IDUs

Knowledge regarding $\mathrm{HCV}^{4}$

Less knowledgeable

More knowledgeable

118

50
86
50

\section{2}

60

38

44.0

69.8

76.0

$2.94(1.34-6.47)$

$4.03(1.58-10.44)$

0.003

0.001

$\begin{array}{ll}85 & 72.0 \\ 85 & 68.0\end{array}$

$0.82(0.48-1.43)$

0.49

\footnotetext{
${ }^{1}$ data missing in 2 cases, ${ }^{2}$ data missing in 1 case, ${ }^{3}$ data missing in 11 cases,,${ }^{4}$ data missing in 3 cases, ${ }^{5}$ data missing in 60 cases
} 
The multivariate analysis initially identified eight variables independently associated with recent syringe borrowing. These included an injecting history of over twelve months and a history of injecting less than 1000 times ever. Although there was no evidence of a significant interaction between these terms, it was deemed more clinically meaningful to combine them to create a new category; this being a group of established, less frequent injectors ( history greater than one year but total injections less than 1000) and a group comprising all remaining IDUs. Introduction of this term into the regression equation maintained a similar goodness of fit. On univariate analysis, the established less frequent injectors were significantly more likely to report recent borrowing ( $85 \%$ versus $67 \%$, odds ratio 2.8 [ $95 \%$ confidence interval 1.2 to 6.7 ], $\mathrm{p}=0.01$ ). The median number of injections per month among the 'established less frequent injectors' was 19 (IQR 7-37) compared to 79 (45-107) among the other IDUs, this difference being highly significant ( MannWhitney U Test, $\mathrm{p}<0.001)$.

Table 4 demonstrates the seven variables independently associated with syringe borrowing. They were parental unemployment, premature cessation of education, injection of more than one substance, being an established less frequent injector, usually injecting in company, perceiving a lower level of risk in sharing with an acquaintance and being more intimately involved with other IDUs. 
Table 4. Logistic regression analysis* of variables independently associated with syringe sharing among 245 IDUs $^{\#}$ in Dublin.

\begin{tabular}{|c|c|c|c|c|}
\hline & Number & Odds ratio & $\begin{array}{r}95 \% \text { confidence } \\
\text { interval }\end{array}$ & $\mathrm{P}$ value \\
\hline \multicolumn{5}{|l|}{ Parental Employment } \\
\hline Unemployment & 96 & 1.0 & & \\
\hline Working & 130 & 0.39 & $0.18-0.82$ & 0.01 \\
\hline Unknown & 19 & 0.58 & $0.085-3.94$ & 0.58 \\
\hline
\end{tabular}

Education

$\begin{array}{lrrrr}\text { Early school leaver }(<15 \text { yo }) & 68 & 1.0 & & \\ \text { Left @ } 15 \text { or over } & 177 & 0.38 & 0.17-0.87 & 0.02\end{array}$

Duration and frequency of injecting

Established infrequent IDU ${ }^{+}$

Number of substances injected

$\begin{array}{lrrrr}\text { One } & 92 & 1.0 & & \\ \text { Two } & 78 & 7.82 & 3.14-19.47 & <0.001 \\ \text { More than two } & 75 & 9.20 & 3.55-23.81 & <0.001\end{array}$

Usual company when injecting

$\begin{array}{lrrrr}\text { Alone } & 47 & 1.0 & & \\ \text { One other IDU } & 83 & 3.53 & 1.37-9.10 & 0.009 \\ \text { Two or more other IDUs } & 50 & 5.16 & 1.84-14.50 & 0.002 \\ \text { Unknown } & 60 & 18.36 & 5.14-65.60 & <0.001\end{array}$

Closest relationship with other IDU

\begin{tabular}{|c|c|c|c|c|}
\hline Sexual partner & 83 & 2.95 & $1.01-8.87$ & 0.05 \\
\hline Close friend & 105 & 1.38 & $0.54-3.57$ & 0.50 \\
\hline 1 st degree relative & 17 & 5.57 & $1.18-26.25$ & 0.03 \\
\hline Acquaintance & 40 & 1.0 & & \\
\hline ived danger in sharing wit & & & & \\
\hline Not extremely dangerous & 114 & 1.0 & & \\
\hline Extremely dangerous & 124 & 0.50 & $0.24-1.01$ & 0.05 \\
\hline Unknown & 7 & 1.33 & $0.12-8.60$ & 0.82 \\
\hline
\end{tabular}

\footnotetext{
* The proportion of variance explained by the model was determined by calculating the Nagelkerke $\mathrm{R}^{2}$ value, which was 0.42 .

\# One case excluded because of missing data

+ 'Established less frequent IDUs' are those who have been injecting for more than 12 months but have injected less than 1000 times in total.
}

\section{Discussion}

Syringes continue to be borrowed by the majority of IDUs in Dublin, at least on an occasional basis. Almost one quarter of IDUs borrowed a syringe frequently ( more often than one in every ten injections ) while almost half of the study group borrowed occasionally ( less than one in ten 
injections ). Only $12.6 \%$ had completely avoided borrowing spoons or filters from other IDUs. 'Halving' was frequently practised. This high level of recent unsafe injecting in this young population is both disappointing and worrying. It does however help to explain the very early acquisition of hepatitis $\mathrm{C}$ infection by IDUs in Dublin. ${ }^{28}$ The proportion reporting recent sharing is greater than that detected elsewhere and is also greater than that found by Dorman six years previously in Dublin. ${ }^{10}$ This can be explained in part by the fact that the population examined in this study is substantially younger than that examined in these other studies and, in common with previous research, we found that younger age was associated with borrowing. Among older IDUs, over the age of 25 years, we found that $55 \%$ had borrowed recently, which is similar to Dorman's finding and approaches the level of sharing reported elsewhere. Our data does not support a hypothesis that unsafe injecting has reduced in conjunction with the expanded harm reduction program.

Although younger age was associated with syringe borrowing on univariate analysis, it ceased to be significantly associated with borrowing when the confounding effect of other variables was controlled for via logistic regression. In common with other studies, we found that polydrug injectors are more likely to inject unsafely. ${ }^{15,19}$ Our data suggests that those who inject benzodiazepines in addition to heroin appear to be at particularly high risk. Increased unsafe injecting by this group has also been reported from Australia. ${ }^{31}$

It may seem self evident that those who usually inject in company are more likely to report syringe borrowing. However, IDUs are generally advised to inject in company as it reduces the risk of accidental overdose. ${ }^{32}$ Both avoidance of accidental death and reducing the occurrence of unsafe 
injecting are worthy goals of harm reduction. In this instance, taking steps to reduce the former may have the impact of increasing the latter.

Strathdee found that the HIV prevalence among IDUs was increased in those with unstable accommodation arrangements and poorer education. ${ }^{4}$ We found that premature cessation of education and a background of parental unemployment were associated with increased reporting of syringe borrowing. While it is generally accepted that these markers of past 'social deprivation' or 'social exclusion' are associated with increased occurrence of drug use and general health risk behaviour, ${ }^{33}$ we are unaware of other studies which demonstrate that such historical features predict current unsafe injecting within populations of IDUs.

Within this group of relatively novice IDUs, the association between injecting history and recent borrowing emerged as being quite complex. The group who were identified as being most likely to report borrowing were those who had been injecting for more than a year but had injected less than 1000 times in total. The regression equation indicated that this group of 'established less frequent injectors' were much more likely than other IDUs to report borrowing. The reasons for this are unclear. Although 'frequency of injecting on injecting days' was not significantly associated with recent syringe borrowing, it may be that the 'established less frequent injectors' inject more opportunistically and become complacent over time about sharing with other IDUs. Clinically, as a group of opiate users attending treatment, they are likely to be viewed with less general concern than other IDUs with newer or greater habits. This may also result in them receiving a less vigorous harm reduction message or possibly viewing the message as less relevant to themselves. 
Numerous studies have highlighted that among IDUs who borrow syringes, they are most likely to borrow from another IDU who is well known or of 'close social proximity'. 7,8,17,18,20-22 Our study used a novel method to stratify IDUs in terms of their social proximity to other IDUs. We found that those whose only contact with other IDUs was quite distant (other IDUs were viewed only as acquaintances) were less likely to report recent borrowing when compared to those whose sexual partner injected. However, no significant difference emerged between the 'acquaintance' category and the 'close friend' category when confounding was controlled in the multivariate analysis.

IDUs who perceived less risk or dangerousness in borrowing from acquaintances were more likely to report recent borrowing. As the perception of risk was measured following the borrowing behaviour, one cannot assume that it necessarily preceded borrowing. Plumridge has described how injecting drug users tend to view themselves as 'careful and responsible' despite engaging in occasional risky injecting practices. ${ }^{23}$ Festinger's theory on cognitive dissonance suggests that cognitions and behaviours will each tend to alter in response to changes in the other to ensure that they 'fit'. ${ }^{34,35}$ This theory would predict that individuals who have engaged in a risk behavior will tend to moderate their perception of risk regarding that activity in order to reduce the dissonance between what they have done and their belief that they are 'careful and responsible'. In any case, it is the demonstrated significant association between syringe borrowing and reduced perception of risk that is important clinically, rather than the direction of causality. This finding suggests that exploration of cognitions around unsafe injecting practices, including perception of dangerousness, could prove a useful area of focus for harm reduction interventions. In a collaborative process between health worker and IDU, beliefs regarding a lack of risk, either generalised or person specific, could be explored and challenged. Alteration of these cognitions towards a perception of greater risk should have the effect of reducing the occurrence of future 
unsafe injecting, as such a behavior would then be dissonant with the 'newly' acquired beliefs. We recognise that provision of such an additional intervention would have resource, training and financial implications for addiction services. There is some preliminary evidence in the literature that cognitive approaches can impact on injecting risk behaviour. ${ }^{36}$

The limitations of this study include the fact that not all eligible individuals were interviewed and that those who did participate were all recruited from treatment settings. Hence, results cannot necessarily be extrapolated to those IDUs who do not attend treatment. The validity of self reported risk behaviours could be questioned but there is a substantial body of evidence which suggests that it is reported with acceptable reliability. ${ }^{37}$ Some studies have found that higher rates of risk behavior can be detected with more detailed data collection instruments, as was used in this study. ${ }^{38}$ This may account in part for the relatively high rate of syringe borrowing found in this study. The absence of HIV and hepatitis C test results represents an additional limitation of this study.

The rate of unsafe injecting detected in this study has worrying implications for the ongoing health of IDUs in Dublin. Although Dublin has maintained a low HIV prevalence and incidence during the 1990 's, ${ }^{29}$ our findings indicate that HIV rates could escalate. There can be no expectation that the incidence of hepatitis $\mathrm{C}$ will fall unless there are substantial reductions in the rates of unsafe injecting. Like many cities in Europe and Australia, Dublin has put in place an extensive and reasonably accessible harm reduction program. Now that this infrastructure exists, we perceive a need for the development of more sophisticated and individualised approaches to harm reduction. When dealing with IDUs, greater attention needs to be paid to the social context in which each particular individual injects and shares. Their unique attitudes and beliefs regarding unsafe 
injecting require exploration, and alteration if necessary. An intervention incorporating these key elements should be developed and evaluated.

\section{References}

1. Donahue, J.G., Munoz, A., Ness, P.m., Brown, D.E., Yawn, D.H., McAllister, H.A., Reitz, B.A. \& Nelson, K.E. (1992) The declining risk of post-transfusion hepatitis C virus infection. New England Journal of Medicine, 327, 369-373.

2. Des Jarlais, D.C., Marmor, M., Paone, D., Titus, S., Shi, Q., Perlis, T., Jose, B. \& Friedman, S.R. (1996) HIV incidence among injecting drug users in New York City syringe-exchange programs. Lancet, 348, 987-991.

3. Des Jarlais, D.C, Friedmann, P., Hagan, H. \& Friedman, S.R. (1996) The protective effect of AIDS-related behavioral change among injection drug users: a cross-national study. American Journal of Public Health,86, 1780-1785.

4. Strathdee, S.A., Patrick, D.M., Currie, S.L., Cornelisse, P.G.A., Rekart, M.L., Montaner, J.S.G., Schecter, M.T. \& O'Shaughnessy, M.V. (1997) Needle exchange is not enough: lessons from the Vancouver injecting drug use study. AIDS, 11, 59-65.

5. Van Ameijden, E.J., Van den Hoek, J.A., Mientjes, G.H. \& Coutinho, R.A. (1993) A longitudinal study on the incidence and transmission patterns of HIV, HBV and HCV infection among drug users in Amsterdam. European Journal of Epidemiology, 9, 255-262.

6. Hagan, H., McGough, J.P., Thiede, H., Weiss, N.S., Hopkins, S. \& Alexander, E.R. (1999) Syringe exchange and risk of infection with hepatitis B and C viruses. American Journal of Epidemiology, 149, 203-213. 
7. Gossop, M., Griffiths, P., Powis, B., Williamson, S., Fountain, J. \& Strang, J. (1997)

Continuing drug risk behaviour: shared use of injecting paraphernalia among London heroin injectors. AIDS Care, 9, 651-660.

8. Kemp, R., Miller, J., Lungley, S. \& Baker, M. (1998) Injecting behaviours and prevalence of hepatitis B,C and D markers in New Zealand injecting drug user population. New Zealand Medical Journal, 111, 50-53.

9. Stark, K., Bienzle, U., Vonk, R. \& Guggenmoos-Holzmann, I. (1997) History of syringe sharing in prison and risk of hepatitis B virus, hepatitis C virus, and human immonodeficiency virus infection among injecting drug users in Berlin. International Journal of Epidemiology, 26, 1359-1366.

10. Dorman, A., Keenan, E., Schuttler, C., Merry, J. \& O’Connor, J.J. (1997) HIV risk behaviour in Irish intravenous drug users. Irish Journal of Medical Science, 166, 235-238.

11. Cassin, S., Geoghegan, T. \& Cox, G. (1998) Young injectors: A comparative analysis of risk behaviour. Irish Journal of Medical Science, 167, 234-237.

12. Fennema, J.A., Van Ameijden, E.J.C., Van den Hoek, A. \& Coutinho, R.A. (1997) Young and recent-onset injecting drug users are at higher risk for HIV. Addiction, 92, 1457-1465.

13. Saxon, A.J., Calsyn, D.A. \& Kackson, T.R. (1994) Longitudinal changes in injection behaviours in a cohort of injection drug users. Addiction, 89, 191-202.

14. Carruthers, S. \& Loxley, W. (1995) Hepatitis C and young drug users: are they about to join the epidemic. Australian Journal of Public Health, 19, 421-424.

15. Peters, A., Davies, T. \& Richardson, A. (1998) Multi-site samples of injecting drug users in Edinburgh: prevalence and correlates of risky injecting practices. Addiction, 93, 253-267. 
16. Stark, K., Muller, R., Wirth, D., Bienzle, U., Pauli, G \& Guggenmoos-Holzmann, I. (1995) Determinants of HIV infection and recent risk behaviour among injecting drug users in Berlin by site of recruitment. Addiction, 90, 1367-1375.

17. Darke, S., Swift, W., Hall, W. \& Ross, M. (1994) Predictors of injecting and injecting risktaking behaviour among methadone maintenance clients. Addiction, 89, 311-316.

18. Baker, A., Kochan, N., Dixon, J., Wodak, A. \& Heather, N. (1995) HIV risk-taking behaviour among injecting drug users currently, previously and never enrolled in methadone treatment. Addiction, 90, 545-554.

19. Davies, A.G., Dominy, N.J., Peters, A.D. \& Richardson, A.M. (1996) Gender differences in HIV risk behaviour of injecting drug users in Edinburgh. AIDS Care, 8, 517-527.

20. Wolk, J., Wodak, A., Morlet, A., Guinan, J.J. \& Gold J. (1990) HIV-related risk-taking behaviour, knowledge and serostatus of intravenous drug users in Sydney. Medical Journal of Australia, 152, 453-457.

21. Ross, M.W., Wodak, A., Stowe, A. \& Gold, J. (1994) Explanations for sharing injection equipment in injecting drug users and barriers to safer drug use. Addiction, 89, 473-479.

22. Loxley, W. \& Ovenden, C. (1995) Friends and lovers: needle sharing in young people in Western Australia. AIDS Care, 7, 337-351.

23. Plumridge, E. \& Chetwynd, J. (1998) The moral universe of injecting drug users in the era of AIDS: sharing injecting equipment and the protection of moral standing. AIDS Care, 10, 723733.

24. Garfein, R.S., Doherty, M.C., Monterosso, E.R., Thomas D.L., Nelson, K.E. \& Vlahov, D. (1998) Prevalence and incidence of hepatitis C virus infection among young adult injection drug users. Journal of Acquired Immune Deficiency Syndromes and Human Retrovirology, 18, (Supplement 1), 11-19. 
25. Crofts, N., Caruana, S., Bowden, S. \& Kerger, M. (2000) Minimising harm from hepatitis C virus needs better strategies. British Medical Journal, 321, 899.

26. Taj, R., Keenan, E. \& O’Connor JJ. (1995) A review of patients on methadone maintenance. Irish Medical Journal, 88, 218-219.

27. Smyth, B.P., O'Brien, M. \& Barry, J. (2000)Trends in treated opiate misuse in Dublin: the emergence of chasing the dragon. Addiction, 95, 1217-1223.

28. Smyth, B.P., Keenan, E. \& O’Connor, J.J. (1999) Reduced risk of hepatitis C among shortterm injecting drug users in Dublin, Ireland. Journal of Epidemiology \& Community Health, $53,434-435$.

29. Smyth, B.P., Keenan, E. \& O'Connor, J.J. (1998) Bloodborne viral infection in Irish injecting drug users. Addiction, 93, 1649-1656.

30. WHO Collaborative Study Group. (1993) An international comparison study of HIV prevalence and risk behaviour among drug injectors in 13 cities. Bulletin on Narcotics, 45, 1945.

31. Smyth, B.P., McMahon, J., O’Connor, J.J. \& Ryan, J. (1999) Knowledge regarding hepatitis C among injecting drug users. Drugs: education, prevention and policy, 6, 257-264.

32. Darke, S.G., Ross, J.E. \& Hall, W.D. (1995) Benzodiazepine use among injecting heroin users. Medical Journal of Australia, 162, 645-647.

33. McGregor, C., Darke, S., Ali, R. \& Christie, P. (1998) Experience of non-fatal heroin overdose among heroin users in Adelaide, Australia: circumstances and risk perceptions. Addiction, 93, 701-711.

34. Lowry, R., Kann, L., Collins, J.L. \& Kolbe, L.J. (1996) The effects of socio-economic status on chronic disease risk behavior among US adolescents. Journal of the American Medical Association, 276, 792-797. 
35. Draycott, S. \& Dabbs, A. (1998) Cognitive dissonance 1: An overview of the literature and its integration into theory and practice in clinical psychology. British Journal of Clinical Psychology, 37, 341-353.

36. Makela, K. (1997) Drinking, the majority fallacy, cognitive dissonance and social pressure. Addiction, 92, 729-736.

37. O Neill, K, Baker, A., Cooke, M., Collins, E., Heather, N. \& Wodak, A. (1996) Evaluation of a cognitive-behavioural intervention for pregnant injecting drug users at risk of HIV infection. Addiction, 91, 1115-1125.

38. Darke, S., Hall, W., Heather, N., Ward, J. \& Wodak, A. (1991) The reliability and validity of a scale to measure HIV risk-taking behaviour among intravenous drug users. AIDS, 5, 181-185.

39. Stimson, G.V., Jones, S., Chalmers, C. \& Sullivan, D. (1998) A short questionnaire (IRQ) to assess injecting risk behaviour. Addiction, 93, 337-347. 